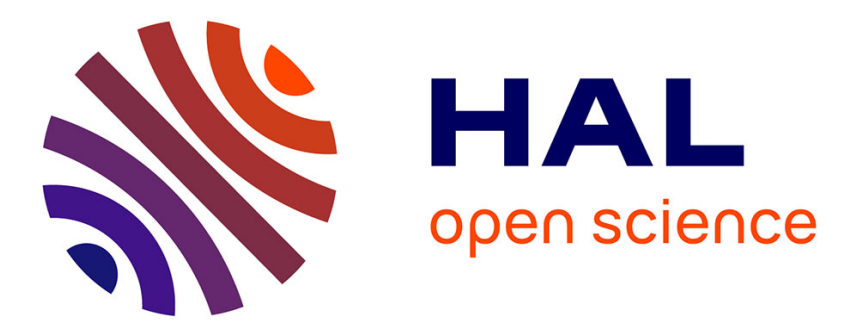

\title{
What is the hydrophobic interaction contribution to the stabilisation of micro-hydrated complexes of trimethylamine oxide (TMAO)? A joint DFT-D, QTAIM and MESP study
}

\author{
Imene Derbali, Emilie-Laure Zins, Mohammad Esmaïl Alikhani
}

\section{To cite this version:}

Imene Derbali, Emilie-Laure Zins, Mohammad Esmail Alikhani. What is the hydrophobic interaction contribution to the stabilisation of micro-hydrated complexes of trimethylamine oxide (TMAO)? A joint DFT-D, QTAIM and MESP study. Journal of Molecular Modeling, 2019, 25, pp.363. $10.1007 / \mathrm{s} 00894-019-4217-y$. hal-02404736

\section{HAL Id: hal-02404736 \\ https://hal.sorbonne-universite.fr/hal-02404736}

Submitted on 11 Dec 2019

HAL is a multi-disciplinary open access archive for the deposit and dissemination of scientific research documents, whether they are published or not. The documents may come from teaching and research institutions in France or abroad, or from public or private research centers.
L'archive ouverte pluridisciplinaire HAL, est destinée au dépôt et à la diffusion de documents scientifiques de niveau recherche, publiés ou non, émanant des établissements d'enseignement et de recherche français ou étrangers, des laboratoires publics ou privés. 


\title{
What is the hydrophobic interaction contribution to the stabilisation of micro-
}

\section{hydrated complexes of trimethylamine oxide (TMAO)? A joint DFT-D, QTAIM and}

\section{MESP study}

\author{
Imene Derbali, ${ }^{1}$ Emilie-Laure Zins, ${ }^{1}$ Mohammad Esmaïl Alikhani ${ }^{1}$
}

1-Sorbonne Université, CNRS, De la Molécule aux Nano-Objets: Réactivité, Interactions Spectroscopies, MONARIS, 75005, Paris France

\begin{abstract}
Micro-hydrated trimethylamine oxide (TMAO) has been investigated using a rangeseparated-hybrid functional including empirical dispersion correction. Electrophilic and nucleophilic sites on TMAO and water clusters have been identified using the molecular electrostatic potential (MESP). The nature of the chemical bonding in the different isomers of the micro-hydrated complexes has been investigated with the topological analysis of the electron density (QTAIM) method. For complexes containing one to four water molecules, the strongest intermolecular interactions consist in hydrogen bonding between the oxygen atom of the TMAO and hydrogen atoms of water molecules. From five water molecules, interactions between water molecules become the main source of stabilization of the most stable isomer. From four stationary points corresponding to the 1:1 (TMAO: $\mathrm{H}_{2} \mathrm{O}$ ) complex, we determined the minimum distances between water molecules and central TMAO allowing the latter molecule to be encapsulated within a water clathrate-type cage. Optimization of TMAO encapsulated within two water cages $\left(5^{12}\right.$ and $\left.5^{12} 6^{2}\right)$ suggests that only in the case of the $5^{12} 6^{2}$ water cage the insertion of TMAO, the preservation of the hydrogen bonding between water molecules is energetically favorable. The interaction energy between one inserted TMAO and the $5^{12} 6^{2}$ water cage was calculated to be around $150 \mathrm{~kJ} / \mathrm{mol}$ with respect to the ground state of two partners. This result suggest that a thorough investigation of mono-hydrated complexes may be particularly relevant to identify the most suitable water cage for encapsulating a given solute.
\end{abstract}

\section{Introduction}

The precise characterization of water-solute interactions is crucial for the understanding of many phenomena, such as hydration of atmospheric molecules, biological processes, clathrate formation and exchange processes of the host molecule. In the case of methane clathrates, it is known that the methane host molecule can be exchanged by injecting $\mathrm{CO}_{2}$. 
From an environmental, energetic and ecological point of view, understanding how this exchange takes place is very important. If the exchange of host molecules in clathrates could be understood and controlled, there would also be other possible applications: storage of $\mathrm{H}_{2}$, transport and reaction in confined environments, to name but a few.

The concept of hydrophobic interactions was introduced around the 1960s to describe the solvation of hydrophobic organic molecules. ${ }^{1,2}$ It seems that a global consensus is emerging on how water molecules arrange themselves around a small hydrophobic solute: ${ }^{3,4,5,6}$ the water molecules would be organized in such a way to maintain as much as possible the existing hydrogen bonding network between water molecules alone. An "exclusion volume" would be formed around small hydrophobic solutes, due to the impossibility of a water molecule to approach the solute without breaking the network of hydrogen bonds between water molecules. The hydration of amphiphilic molecules is more complex, and it has been shown that the hydrophilic part of solutes considerably slows down the dynamic processes of liquid water. It is known that, on the scale of an aqueous solution, amphiphilic molecules, with a hydrophilic part and a hydrophobic part, can modify the local structure and dynamics of water molecules.

These phenomena have been particularly studied in the case of the TMAO molecule.

The hydrophilic part is centered in the vicinity of the oxygen atom. ${ }^{7}$ In aqueous solution, the oxygen atom interacts with three water molecules via interactions of the hydrogen bond type. The hydrophobic part consists of methyls groups. Various advanced studies of ab initio molecular dynamics show, in solution, the existence of three types of water molecules, depending on their position:

$>$ the water molecules with a maximum distance between the oxygen of the TMAO and one of the hydrogen of these water molecules of $2.1 \AA$ are called "hydrophilic water molecules" by D. Marx et al. ${ }^{8,9}$ Three water molecules meet this requirement, and together with the TMAO molecule, they constitute the "supermolecular solvation complex" in the spectral decomposition model introduced by D. Marx et al. for the theoretical analysis of the THz spectra of zwitterionic molecules by AIMD (ab initio molecular dynamic) simulation, ${ }^{10}$

$>$ water molecules located beyond this limit, and whose oxygen atom is located within $4.4 \AA$ of one of the carbon atoms of the TMAO are called "hydrophobic water molecules",

$>$ the other water molecules are considered to be bulk water molecules.

These studies provided a precise description of the overall behavior of water molecules around the TMAO in solution: AIMD calculations suggest that methyl groups would not be involved in hydrogen bond interactions. However, the experimental and theoretical molecular-scale study of other organic solutes showed that a water molecule could act as 
an acceptor of hydrogen bonds in weak secondary interactions with methyls groups. To our knowledge, at the molecular level, only one theoretical study of TMAO: $\left(\mathrm{H}_{2} \mathrm{O}\right)_{n}$ hydrated complexes involving an increasing number of water molecules up to about ten, has been carried out. This work was carried out by Hammer et al. in 2011, with DFT calculations at the B3LYP/aug-cc-pVTZ level. ${ }^{11}$ The results obtained suggest that methyls could act as hydrogen bond donors, particularly in complexes containing 5 and 7 water molecules, but the formation of such hydrogen bondings was not demonstrated to date in these complexes.

In order to provide a better understanding of water-solute interactions, we looked for the TMAO: $\left(\mathrm{H}_{2} \mathrm{O}\right)_{n}$ isomers for $1 \leq \mathrm{n} \leq 24$. We characterized the nature of water-water and water-solute interactions in the complexes studied until a hydration sphere was formed around the solute. We were particularly interested in the characterization of interactions:

Detween a water cluster and the hydrophilic part of the TMAO,

$>$ between a water cluster and the hydrophobic part of the TMAO,

$>$ between a clathrate-type water cage and the TMAO.

\section{Method}

Intermolecular interactions such as Burgi-Dunitz hydrogen bonds as well as interactions with a strong dispersive contribution have been demonstrated in the micro-hydrated complexes around small, weakly polar organic solutes. Even in the case of a small solute $\mathrm{S}$, the number of isomers for an $\mathrm{S}:\left(\mathrm{H}_{2} \mathrm{O}\right)_{n}$ complex is quickly increasing when $\mathrm{n}$ increases, and it is not always easy to identify the most stable isomer using DFT or ab initio calculations based on the chemist's simple intuition. Politzer and Murray have shown that all these interactions come from electrostatic effects in the sense of Hellman-Feynmann's theorem. $12,13,14$ This is the reason why the study of the molecular electrostatic potential (MESP) of isolated partners makes it possible to propose preferred directions of approach, before geometry optimizations. Gadre et al. introduced the topology of the MESP function to study the formation of hydrated or other complexes. Another approach, simpler and directly based on the physical nature of interactions between molecules at long distances, has been proposed: it consists in studying the MESP of isolated partners and seeking all associations to maximize interactions between complementary sites. The initial structures thus obtained are then optimized. Which "isolated partners" to choose for the study of an $\mathrm{S}:\left(\mathrm{H}_{2} \mathrm{O}\right)_{n}$ complex? Different choices are possible: $\mathrm{S}$ and $\left(\mathrm{H}_{2} \mathrm{O}\right)_{n}, \mathrm{~S}:\left(\mathrm{H}_{2} \mathrm{O}\right)$ and $\left(\mathrm{H}_{2} \mathrm{O}\right)_{n-1}$, as well as $\mathrm{S}:\left(\mathrm{H}_{2} \mathrm{O}\right)_{x}$ and $\left(\mathrm{H}_{2} \mathrm{O}\right)_{y}$, with $\mathrm{x}+\mathrm{y}=\mathrm{n}$. All these starting points should be considered when looking for the TMAO: $\left(\mathrm{H}_{2} \mathrm{O}\right)_{n}$ most stable isomers.

To further understand the formation of hydrogen bondings and other interactions, the topological analysis of the Electron Localization Function (ELF) ${ }^{15,16}$ of isolated water and TMAO molecules is particularly relevant, since it allows the identification of valence basins. 
Protonated basins can be localized and characterized, as well as electron pairs in keeping with the Lewis structures. ${ }^{17,18}$ Furthermore, after geometry optimization, all the hydrated complexes were further studied by means of the QTAIM ${ }^{19}$ approach in order to analyze both qualitatively and quantitatively the intermolecular interactions involved in the complexes. We were particularly interested in quantifying the water-water interaction and the watersolute interactions in order to shed some light on the origins of the stability of the complexes.

All the calculations were carried out with the Gaussian09 software. ${ }^{20}$ Dispersion-corrected density functionals within the density functional theory (DFT-D) are methods of choice for quantum chemical calculations on large systems including long-range, non-covalent interactions such as hydrogen bondings and electrostatic interactions. For the present study, we used the LC- $\omega$ PBE functional ${ }^{21,22,23}$ in combination with the $6-311++G(d, p)$ triple $\zeta$ Pople basis set. The Grimme empirical dispersion correction with Becke-Johnson damping function (GD3BJ) ${ }^{24}$ was applied (using the "EmpiricalDispersion=GD3BJ" keyword). Furthermore, to deliver more accurate results, two additional keywords were used for the optimization calculations: $\mathrm{scf}=$ Tight Int=UltraFine. All the geometry optimization have been supplemented by frequency calculation to ascertain the nature of the stationary point (transition state versus local minimum).

The zero point energy (ZPE) correction was taken into account in all the energy calculations. Four energy differences were calculated for all the TMAO: $\left(\mathrm{H}_{2} \mathrm{O}\right)_{n}$ isomers (Table 1):

$>$ the binding energy corrected for the ZPE, D0, was calculated as the difference between the energy of the TMAO: $\left(\mathrm{H}_{2} \mathrm{O}\right)_{n}$ complex ( $\left.\mathrm{E}_{\mathrm{TMAO}:(\mathrm{H} 2 \mathrm{O}) \mathrm{n}}\right)$ and the ones of isolated TMAO (E $\left.\mathrm{E}_{\text {TMAO }}^{\text {isolated }}\right)$ and $\left(\mathrm{H}_{2} \mathrm{O}\right)_{n}$ partners $\left(\mathrm{E}_{(\mathrm{H} 2 \mathrm{O}) \mathrm{n}}^{\text {most stable }}\right)$ in their most stable geometries,

$>$ the interaction energy, I.E., was calculated as the difference between $\mathrm{E}_{\mathrm{TMAO}:(\mathrm{H} 2 \mathrm{O}) \mathrm{n}}$ and the sum of $\mathrm{E}_{\mathrm{TMAO}}^{\text {isolated }}$ with $\mathrm{n}$ times the energy of an isolated water molecule $\left(\mathrm{nE}_{(\mathrm{H} 2 \mathrm{O})}^{\text {isolated }}\right)$,

$>\Delta(\mathrm{E})$ was calculated as the difference between the energy of the TMAO: $\left(\mathrm{H}_{2} \mathrm{O}\right)_{n}$ and the energy of the most stable TMAO: $\left(\mathrm{H}_{2} \mathrm{O}\right)_{n}$ isomer,

$>\Delta(\mathrm{G})$ calculated as the difference between the free energy of the TMAO: $\left(\mathrm{H}_{2} \mathrm{O}\right)_{\mathrm{n}}$ and the free energy of the most stable TMAO: $\left(\mathrm{H}_{2} \mathrm{O}\right)_{n}$ isomer.

Table 1: Energy differences that were used throughout this work to characterize the stabilization of the isomers studied.

\begin{tabular}{|c|c|}
\hline $\mathrm{D} 0=\mathrm{E}_{\mathrm{TMAO}:(\mathrm{H} 2 \mathrm{O}) \mathrm{n}}-\left[\mathrm{E}_{\mathrm{TMAO}}^{\text {isolated }}+\mathrm{E}_{(\mathrm{H} 2 \mathrm{O}) \mathrm{n}}^{\text {most stable }}\right]$ & $\Delta(\mathrm{E})=\mathrm{E}_{\mathrm{TMAO}:(\mathrm{H} 2 \mathrm{O}) \mathrm{n}}-\mathrm{E}_{\mathrm{TMAO}(\mathrm{H} 2 \mathrm{O}) \mathrm{n}}^{\text {most stable }}$ \\
\hline $\mathrm{I} . \mathrm{E} .=\mathrm{E}_{\mathrm{TMAO}:(\mathrm{H} 2 \mathrm{O}) \mathrm{n}}-\left[\mathrm{E}_{\mathrm{TMAO}}^{\text {isolated }}+\mathrm{nE}_{(\mathrm{H} 2 \mathrm{O})}^{\text {isolated }}\right]$ & $\Delta(\mathrm{G})=\mathrm{G}_{\mathrm{TMAO}:(\mathrm{H} 2 \mathrm{O}) \mathrm{n}}-\mathrm{G}_{\mathrm{TMAO}:(\mathrm{H} 2 \mathrm{O}) \mathrm{n}}^{\text {most stable }}$ \\
\hline
\end{tabular}


The Gaussian09 software was also used to generate the .wfn files further used for the topological analyses. From these .wfn files:

the Topmod ${ }^{25}$ software was used for the topological analysis of the ELF function,

> the Aimall sofware was used for the QTAIM analysis as well as for the MESP analysis. $^{26}$

The structures of the water cages used for the study of the complexes TMAO: $\left(\mathrm{H}_{2} \mathrm{O}\right)_{20}$ and TMAO: $\left(\mathrm{H}_{2} \mathrm{O}\right)_{24}$ were taken from the literature. ${ }^{27,28}$

The main QTAIM topological features of the species herein discussed are presented in Supporting Information S1-S10, and the Cartesian Coordinates of all the complexes are given in Supporting Information S11.

\section{Characterization of isolated TMAO and $\mathrm{H}_{2} \underline{\mathrm{O}}$ partners}

The topological analysis of the TMAO leads to the identification of three particular regions (Figure 1):

$>$ a highly nucleophilic zone located near the oxygen atom

$>$ an electrophilic zone, diametrically opposed to this nucleophilic region. It is an electrophilic region located on the axis of a $\sigma$-bond, which corresponds to the definition of a $\sigma$-hole,

$>$ three weakly electrophilic zones, in the median plane of the molecule, chose to the hydrogen atoms of the methyl groups.

Figure 1: Molecular electrostatic potentials and the topological analysis of the ELF function of the TMAO and water molecules.

Most e $\varphi(\sigma$ hole)

Furthermore, the topology of the ELF function leads to the identification of three monosynaptic basins for the oxygen atom (Figure 1). For sake of comparison, the topological analysis of the isolated water molecule is also presented in Figure 1. 
In the literature, one hydrophilic and one hydrophobic regions are often considered for the TMAO molecule. However, for consistency with the MESP analysis, it is interesting to distinguish three different regions (Scheme 1):

$>$ a hydrophilic region in the vicinity of the oxygen atom; this corresponds to the nucleophile region characterized from the MESP analysis,

a hydrophobic region that is diametrically opposite to the hydrophilic region; this region will be called the "opposite hydrophobic region"; this corresponds to the $\sigma$ hole identified from the MEP analysis,

$>$ a hydrophobic region between the two above-mentioned regions, that will be called the "vicinal hydrophobic region"; this corresponds to the weak electrophile regions identified from the MESP analysis.

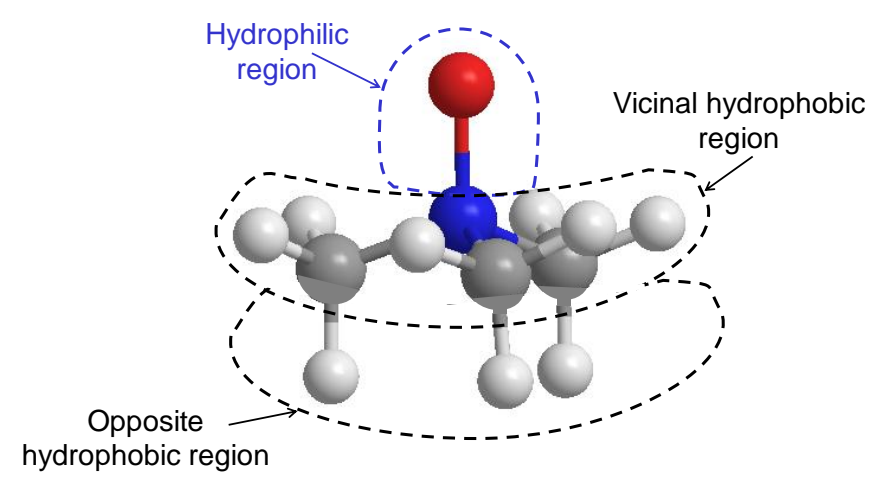

Scheme 1: Identification of three different regions on the surface of the TMAO molecule

\section{Identification and characterization of TMAO: $\left(\mathrm{H}_{2} \mathrm{O}\right)$ isomers}

From the topological analysis, three different directions of approaches of a water molecule relative to the TMAO may be proposed to maximize interactions between complementary sites (Figure 2):

$>$ an approach allowing an interaction between a protonated basin of the water molecule (an electrophilic site) and a monosynaptic basin (a nucleophilic zone) of the TMAO. This approach also makes it possible to consider the formation of a secondary interaction between the nucleophilic zone of the water molecule and the weakly nucleophilic zone of the TMAO (Figure 2A);

an approach in which the electrophilic zone of the water molecule interacts with the most nucleophilic part of the TMAO (Figure 2B);

an approach in which the electrophilic zone of the water molecule interacts with a weaker nucleophilic zone of the TMAO, in the median plane of the solute (Figure 2C). 
A

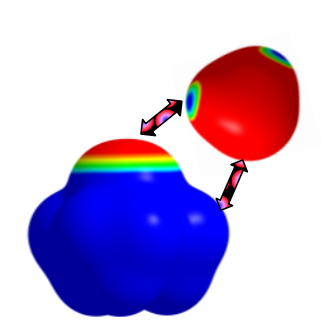

B

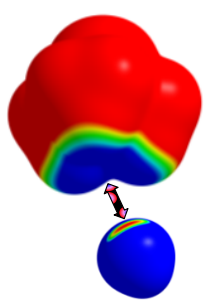

C

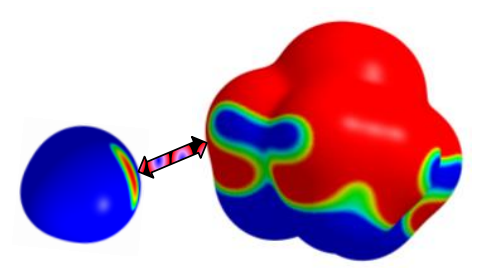

Figure 2: Three different direction of approaches of a water molecule relative to the TMAO molecule leading to the maximization of interactions between complementary sites.

After geometry optimization and frequency calculations, four structures are obtained for the mono-hydrated complex. Two structures correspond to minima on the potential energy surface: they will be denoted as S1 and S2 (Table 2). The two other structures correspond to transition states: they will be denoted as TS1 and TS2 (Figure 3). The S1 isomer corresponds to the global minimum, and lies $38.6 \mathrm{~kJ}^{\mathrm{mol}}{ }^{-1}$ below the S2 isomer. The binding energies for the S1 and S2 isomers are -61.4 and $-13.0 \mathrm{~kJ}^{\mathrm{mol}}{ }^{-1}$, respectively. The QTAIM analysis of the S1 and S2 isomers demonstrates that, in both cases, three water-solute interactions are simultaneously formed (Table 2).

Table 2: Structure, energetic and QTAIM topological features of the TMAO: $\left(\mathrm{H}_{2} \mathrm{O}\right)$ isomers identified at the LC- $\omega$ PBE / 6-311++G(d,p) level of theory. The small green spheres correspond to Bond Critical Points (BCP) and the black lines to Bond Paths (BP), as defined in the QTAIM theory. $\rho(r)$ and $\nabla^{2} \rho(r)$ correspond to the electron density and its Laplacian at the BCP, respectively (the values are given in a.u.).

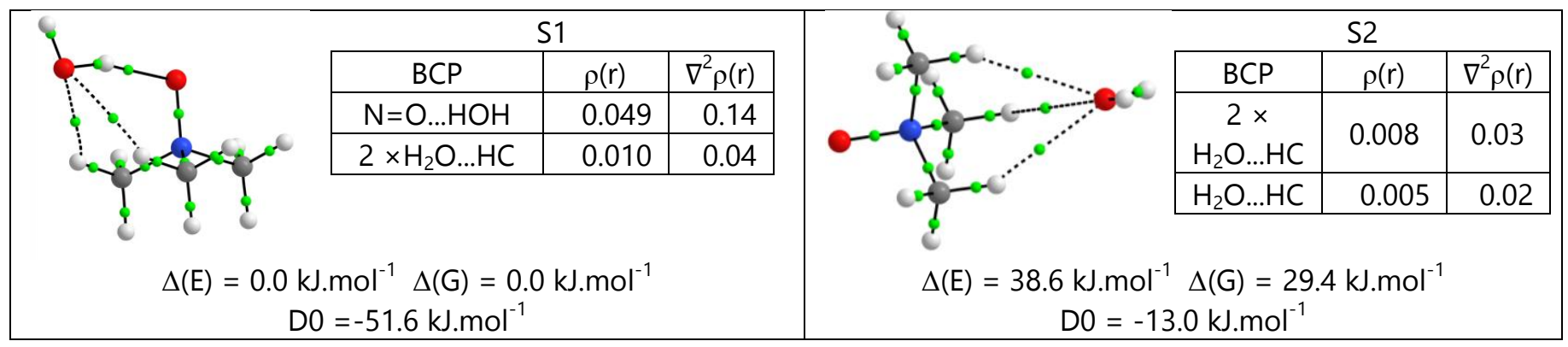

In the S1 isomer, the main interactions consists in an hydrogen bonding between a hydrogen atom of the water molecule and the oxygen atom of the TMAO, in full agreement with structures already proposed in the literature. Simultaneously, two other weak hydrogen bondings involving hydrogen atoms of the "vicinal hydrophobic region" of the TMAO and the oxygen atom of the water molecule, are also identified. Interactions with the hydrogen atoms of the TMAO cause a significant deformation of the main hydrogen bond. Indeed, according to the IUPAC report, in the case of an undisturbed hydrogen bond, the $\mathrm{OHO}$ angle should be close to $180^{\circ} .{ }^{29}$ However, in the $\mathrm{S} 1$ complex, the $\mathrm{OHO}$ angle is equal to $162.7^{\circ}$. For secondary interactions, both $\mathrm{OHC}$ angles are equal to $129.8^{\circ}$. 
In the S2 isomer, the water molecule interacts with the TMAO via the "opposite hydrophobic region". Three weak hydrogen bondings involving a hydrogen atom of each methyl group are identified from the QTAIM analysis. This isomer is significantly less stable than the S1 isomer. However, the negative binding energy shows that the formation of this isomer is energetically possible.

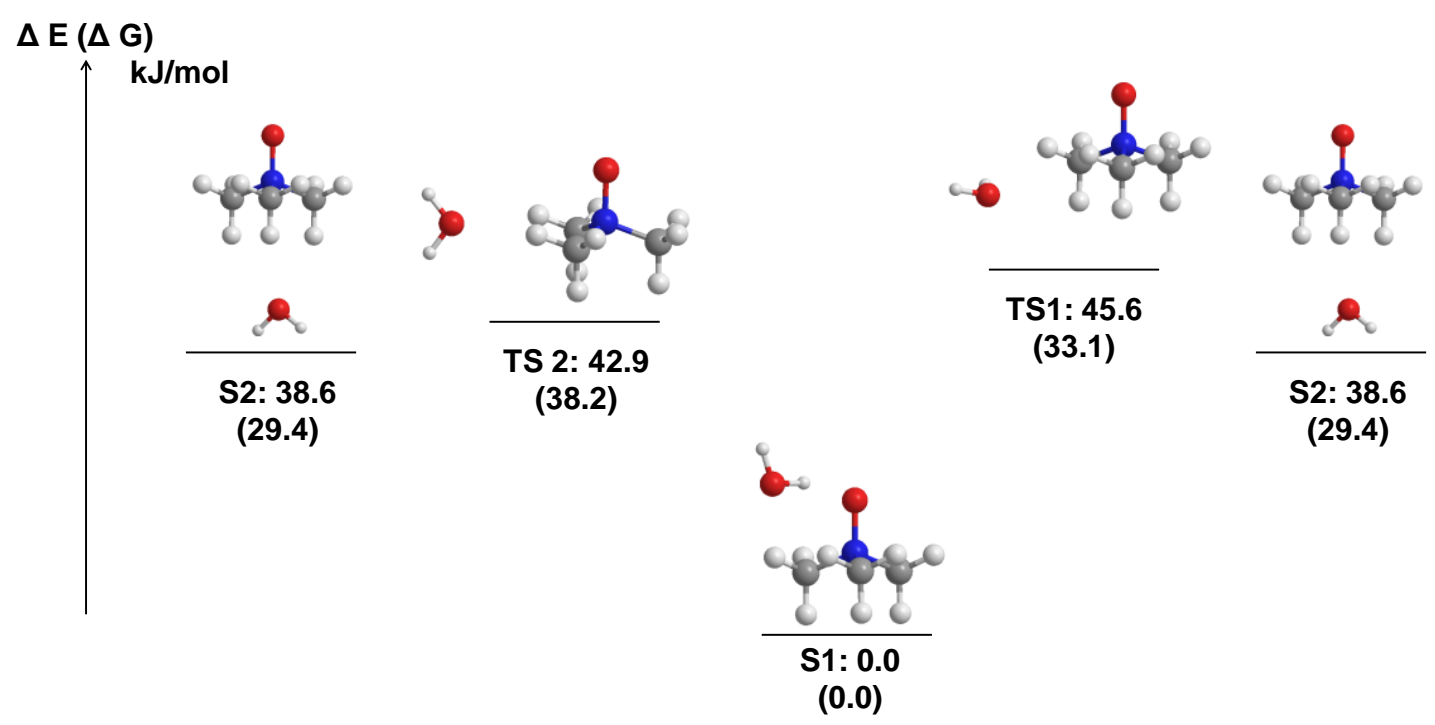

Figure 3: Identification of the global minimum, a local minimum, and two transition states on the potential energy surface of the TMAO: $\left(\mathrm{H}_{2} \mathrm{O}\right)$ isomers at the LC- $\omega$ PBE / 6-311++ $G(d, p)$ level of theory

In the structures corresponding to transition states, the water molecule is solely interacting with the "vicinal hydrophobic region". The TS1 and TS2 species lie 45.6 and $42.9 \mathrm{~kJ}^{\mathrm{mol}}{ }^{-1}$ above the global minimum, respectively, and they both correspond to a switch of the water molecule between the S1 and S2 isomers (Figure 3).

\section{Identification and characterization of TMAO: $\left(\mathrm{H}_{2} \underline{\underline{O}}\right)_{2-9}$ isomers}

As soon as the dihydrated species is considered, many questions arise, and several isomers can be considered:

1. Does the micro-hydration occur with segregation of water molecules as observed with some other organic solutes? The term " water segregation " refers to a water cluster interacting with the solute. This expression being regularly used in the literature, we will employ it in the following of the manuscript.

2. Can the hydrogen bonding between the water molecules observed in the water dimer be preserved in the interaction with the TMAO?

3. Can interactions between water molecules and the hydrophobic part of the TMAO stabilize the TMAO complex: $\left(\mathrm{H}_{2} \mathrm{O}\right)_{2}$ ? 
Several starting points should be used to generate the initial structures for the TMAO: $\left(\mathrm{H}_{2} \mathrm{O}\right)$ complex:

$>$ the TMAO molecule with the water dimer. The analysis of the MESPs suggests two main directions for the approach of these two partners (Figure 4): the electrophilic site and the nucleophilic site of the water dimer may interact with the hydrophilic (nucleophilic) region of the TMAO and the "vicinal hydrophobic (weak electrophilic) region", respectively. Alternatively, the water dimer may interact with the TMAO via a the "opposite hydrophobic (electophilic) region",

$>$ the TMAO: $\left(\mathrm{H}_{2} \mathrm{O}\right)$ complex with an additional water molecule. This corresponds to two different starting points: the $\mathrm{S} 1$ isomer and a water molecule, or the S2 isomer with an additional water molecule.

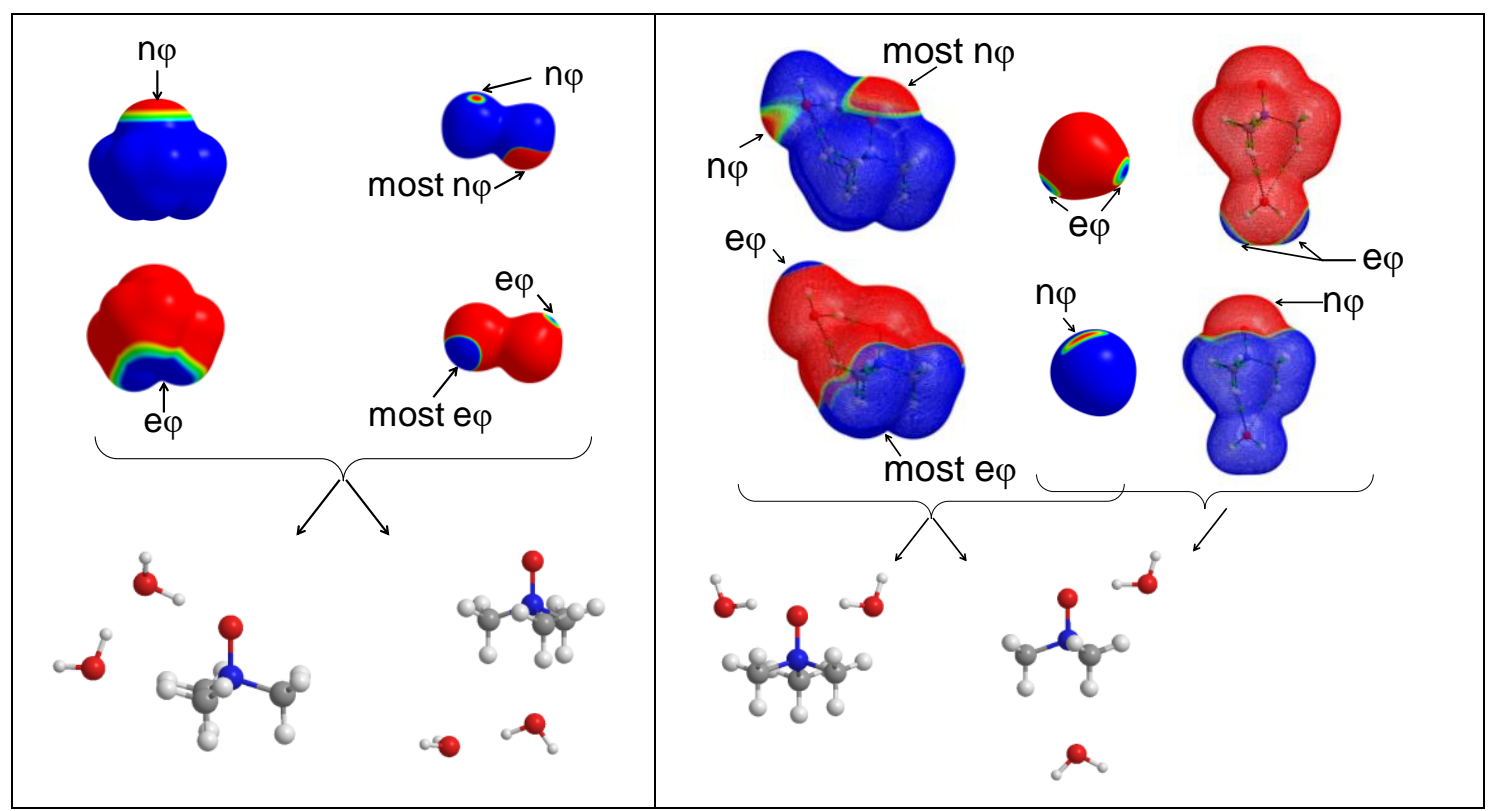

Figure 4: Proposal of two possible preferred approach direction for the water dimer relative to the TMAO molecule, as well as of two possible preferred approach direction for a water dimer relative to the TMAO: $\left(\mathrm{H}_{2} \mathrm{O}\right)$ isomers, based on the molecular electrostatic potential (MESP) analysis. The guess structures thus obtained were used as starting points for the identification of TMAO: $\left(\mathrm{H}_{2} \mathrm{O}\right)_{2}$ isomers prior to geometry optimizations.

After geometry optimizations, four isomers were obtained, all of them corresponding to minima on the PES (Table3):

$>$ In the most stable isomer, the two water molecules interact separately and symmetrically with the TMAO. The two main interactions correspond to hydrogen bondings. As in the case of the S1 isomer of the TMAO:(H2O) complex, the OHO angles are smaller than those of a conventional hydrogen bond, and are $161.5^{\circ}$. Each water molecule is also involved in two secondary interactions of the hydrogen bond type with hydrogen atoms of methyls groups, and the $\mathrm{OHC}$ angles are $130.2^{\circ}$ and $131.3^{\circ}$. The complexation energy is $-80.7 \mathrm{~kJ} . \mathrm{mol}^{-1}$ for this isomer

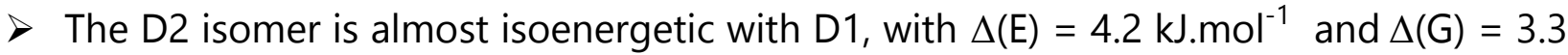
$\mathrm{kJ}_{\mathrm{mol}}{ }^{-1}$. In this isomer, the water dimer interacts with the TMAO molecule. The 
electron density at the $\mathrm{BCP}(\rho(\mathrm{r}))$ corresponding to the hydrogen bond between the two water molecules is 0.040 . In the isolated water dimer, the value is 0.024 . The significant increase of $\rho(r)$ in the complex suggests a cooperative effect due to the formation of three additional interactions with TMAO: a main interaction of the hydrogen bond type with the oxygen atom of TMAO, and two secondary interactions with two hydrogen atoms of the methyls groups. For the interaction between the oxygen atom of the TMAO and the water molecule, the higher value of $\rho(r)$ in the D2 complex (0.058) compared to the S1 and D1 complexes $(0.049$ and 0.043 , respectively) again suggests a cooperative effect. The complexation energy is -76.5 $\mathrm{kJ} . \mathrm{mol}^{-1}$ for this isomer.

$>$ The D3 isomer lies significantly higher in energy, with $\Delta(\mathrm{E})=30.7 \mathrm{~kJ} \cdot \mathrm{mol}^{-1}$ and $\Delta(\mathrm{G})=$ $23.1 \mathrm{~kJ}^{\mathrm{mol}}{ }^{-1}$. In this isomer, one water molecule occupies a position close to the one of the water molecule in the S1 isomer, while the other water molecule occupies a position close to the one of the water molecule in the S2 isomer. The QTAIM analysis reveals tjat each water molecule is involved in three non-covalent interactions with

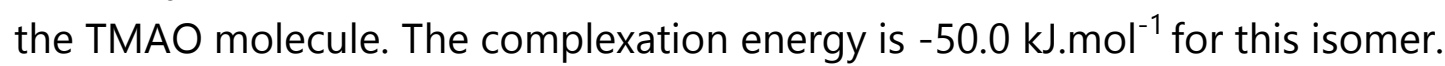

$>$ In the D4 isomer, the water dimer is in interaction with the TMAO molecule via the "opposite hydrophobic region".

Table 3: Structure, energetic and QTAIM topological features of the TMAO: $\left(\mathrm{H}_{2} \mathrm{O}\right)$ isomers identified at the LC-wPBE / 6-311++G(d,p) level of theory. The small green spheres correspond to Bond Critical Points (BCP) and the black lines to Bond Paths (BP), as defined in the QTAIM theory. $\rho(r)$ and $\nabla^{2} \rho(r)$ correspond to the electron density and its Laplacian at the BCP, respectively (the values are given in a.u.).

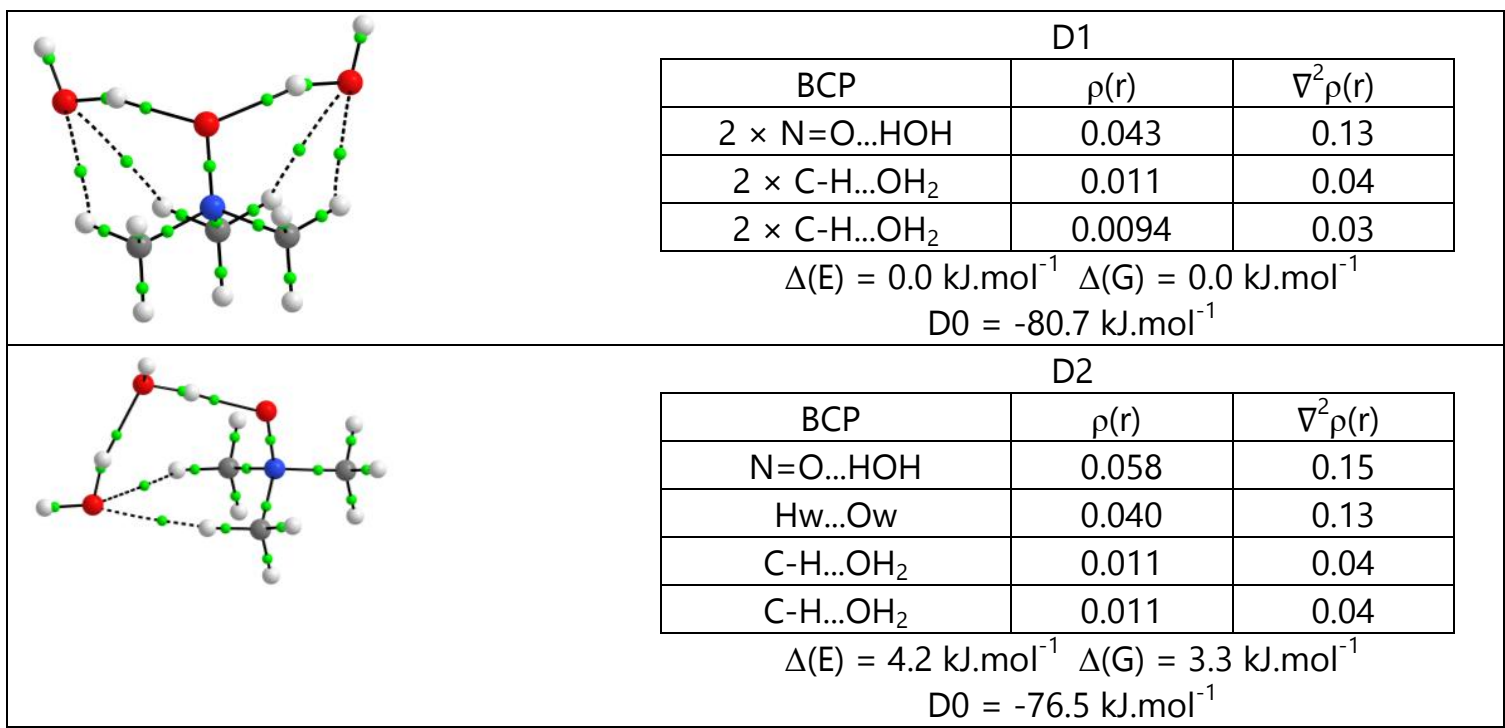




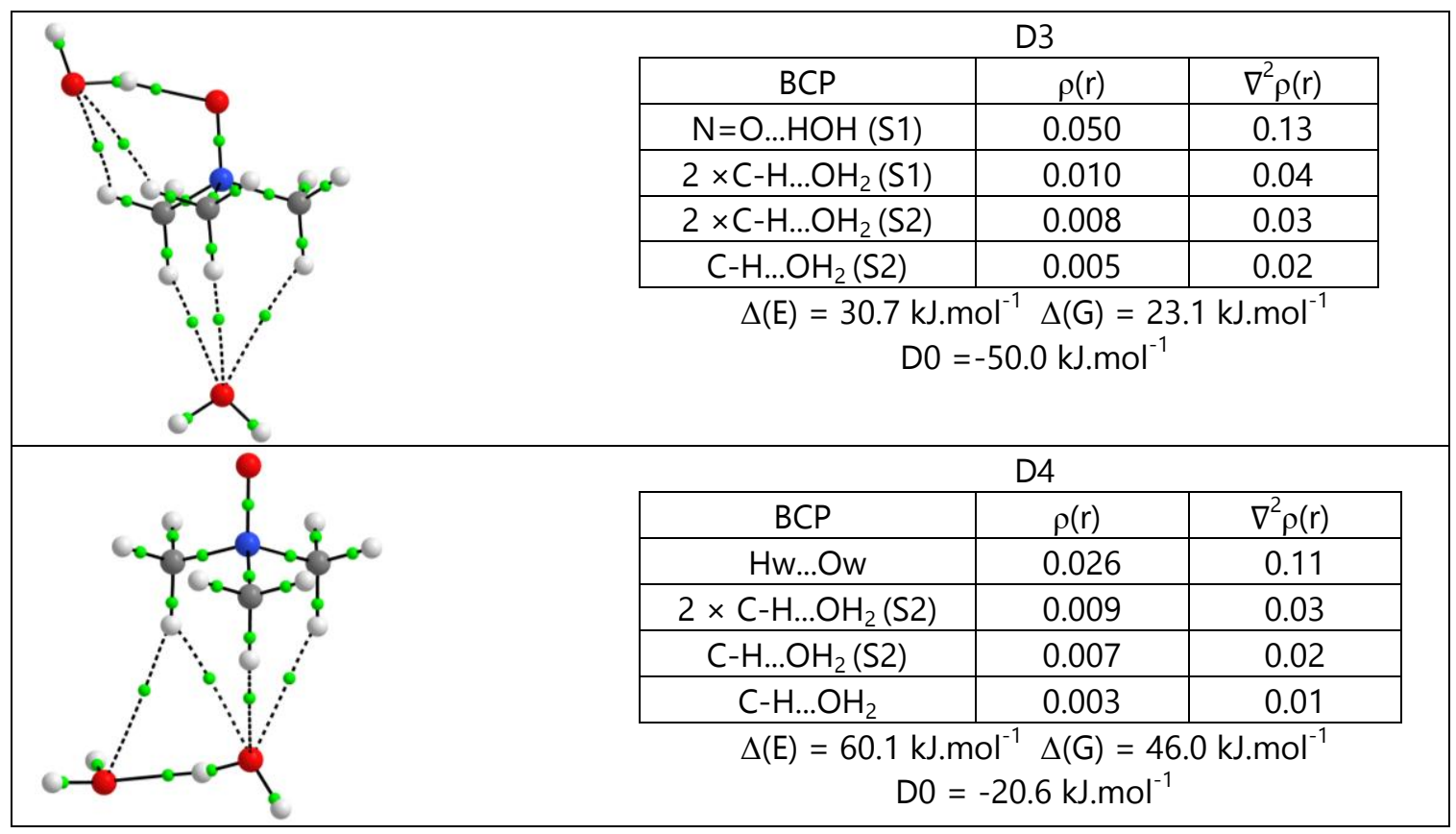

Table 4: Comparison of the geometric and topological features of the hydrogen bonding between water molecules in the water dimer and in the D2 and D4 isomers.

\begin{tabular}{|c|c|c|c|}
\hline Complex & $\mathrm{d}_{\text {Hw... }}(\AA)$ & $\rho(\mathrm{r})$ & $O-\widehat{H} \ldots O\left({ }^{\circ}\right)$ \\
\hline$\left(\mathrm{H}_{2} \mathrm{O}\right)_{2}$ & 1.93 & 0.024 & 175.9 \\
\hline $\mathrm{D} 2$ & 1.73 & 0.040 & 162.7 \\
\hline $\mathrm{D} 4$ & 1.88 & 0.026 & 172.0 \\
\hline
\end{tabular}

Data reported in the Table 4 demonstrate that the water dimer is not dramatically affected by the interaction with the "opposite hydrophobic region" of the TMAO: the intermolecular distance between water molecules, $\rho(\mathrm{r})$ and the $O \widehat{-H} \ldots O$ angle are close to the ones observed in the isolated water dimer. This is in strong contrast with what is observed when both water molecules interact with the hydrophilic and the "vicinal hydrophobic region" : in the D2 isomer, the $d_{H w . . .0 w}$ distance is significantly shorter (by $0.20 \AA$ ) than that of the dimer water, suggesting a strengthening of the water/water interaction. The concomitant increase of $\rho(r)$ in the D2 isomer relative to the $\left(\mathrm{H}_{2} \mathrm{O}\right)_{2}$ complex confirms the strengthening of the water-water interaction. In addition, one of the water molecules of the D2 isomer occupies a similar position to that of the water molecule of the $\mathrm{S} 1$ isomer, near the oxygen atom of the TMAO, and it is interesting to compare the characteristics of these interactions (Table 5).

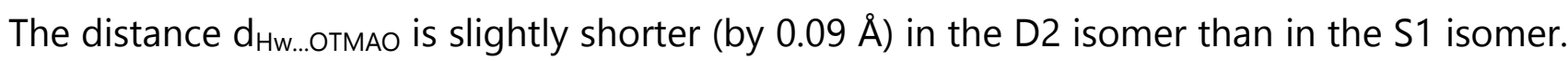
In addition, for this interaction, $\rho(r)$ is significantly higher in the $D 2(0.058)$ isomer than in the S1 (0.049) isomer. The interaction of the water cluster with the hydrophilic part of the TMAO therefore has a cooperative effect, resulting in enhanced water-water and watersolute interactions. This is not the case for the interaction of the water cluster with the hydrophobic part of the TMAO solute (Table 5). 
Table 5: Comparison of the geometric and topological features of the hydrogen bonding between water molecules and the solute in the S1 and D2 isomers, as well as in the S2 and D4 isomers.

\begin{tabular}{|c|c|c|c|c|}
\hline Complex $\quad$ Feature & \multicolumn{3}{|c|}{ Interacting atoms, $d_{\text {water...TMAO }}(\AA), \rho(r)$} & $O_{\mathrm{w}}-\widehat{H_{\mathrm{w}} \cdots} O_{\mathrm{TMAO}}\left({ }^{\circ}\right)$ \\
\hline S1 & $\mathrm{H}_{\text {water }} \ldots \mathrm{O}_{\text {TMAO }}$ & 1.69 & 0.049 & 162.6 \\
\hline D2 & $\mathrm{H}_{\text {water }} . . \mathrm{O}_{\text {TMAO }}$ & 1.60 & 0.058 & 176.4 \\
\hline $\mathrm{S} 2$ & $\mathrm{O}_{\text {water }} . . . \mathrm{H}_{\text {TMAO }}$ & $\begin{array}{c}2 \times 2.55 \\
2.75 \\
\end{array}$ & $\begin{array}{c}2 \times 0.008 \\
0.005\end{array}$ & \\
\hline D4 & $\mathrm{O}_{\text {water }} \ldots \mathrm{H}_{\text {TMAO }}$ & $\begin{array}{c}2 \times 2.48 \\
2.59 \\
3.12\end{array}$ & $\begin{array}{c}2 \times 0.009 \\
0.007 \\
0.003\end{array}$ & \\
\hline
\end{tabular}

A similar approach was used to identify and characterize the TMAO: $\left(\mathrm{H}_{2} \mathrm{O}\right)_{n}$ complexes, $3 \leq n$ $\leq$ 9. Finally, 45 stable isomers were found. The QTAIM features of the intermolecular interactions as well as the energetic features of the complexes are presented in Supporting Information S1 - S9.

Table 6 shows several structures for complexes containing 3 to 9 water molecules:

$>$ the most stable complexes herein obtained,

$>$ complexes involving the highest fraction of hydrophilic water-solute interactions,

$>$ complexes involving the highest fraction of hydrophobic water-solute interactions.

Fully consistent with earlier studies presented in the literature, ${ }^{8-11}$ the most stable isomer for the TMAO: $\left(\mathrm{H}_{2} \mathrm{O}\right)_{3}$ complex consists of three water molecules each forming an hydrogen bonding with the oxygen atom of the TMAO. It is worth noting that no interaction between the water molecules exists in the most stable isomer. This is consistent with what is also obtained for the complex containing two water molecules. However, it is interesting to note that TMAO does not lead to segregation of water molecules, unlike other solutes. ${ }^{30-37}$

The fact that the most stable TMAO: $\left(\mathrm{H}_{2} \mathrm{O}\right)_{2}$ and TMAO: $\left(\mathrm{H}_{2} \mathrm{O}\right)_{3}$ isomers consist of isolated water molecules interacting with the solute rather than slightly perturbed water dimer and water trimer can easily be understood by considering the interaction energies between the TMAO and a single water molecule on the one hand, and between water molecules in the water dimer and water trimer on the other hand. Indeed, the interaction energy between a single water molecule and TMAO is equal to $-61.4 \mathrm{~kJ} \mathrm{~mol}^{-1}$ (Table 2), whereas the interaction energy in the water dimer and trimer are calculated to be -16.1 and $-53.8 \mathrm{~kJ}^{\mathrm{mol}}{ }^{-1}$, respectively at the same level of theory (Supporting Information). A quantitative analysis of the MESP features of isolated partners also shed some light on their electrophilic and nucleophilic strengths (Figure 5): the oxygen atom of the TMAO molecule is a stronger nucleophile than the oxygen atom of the water molecule. As a consequence, the TMAO molecule is a better hydrogen-bond acceptor than the water molecule. 


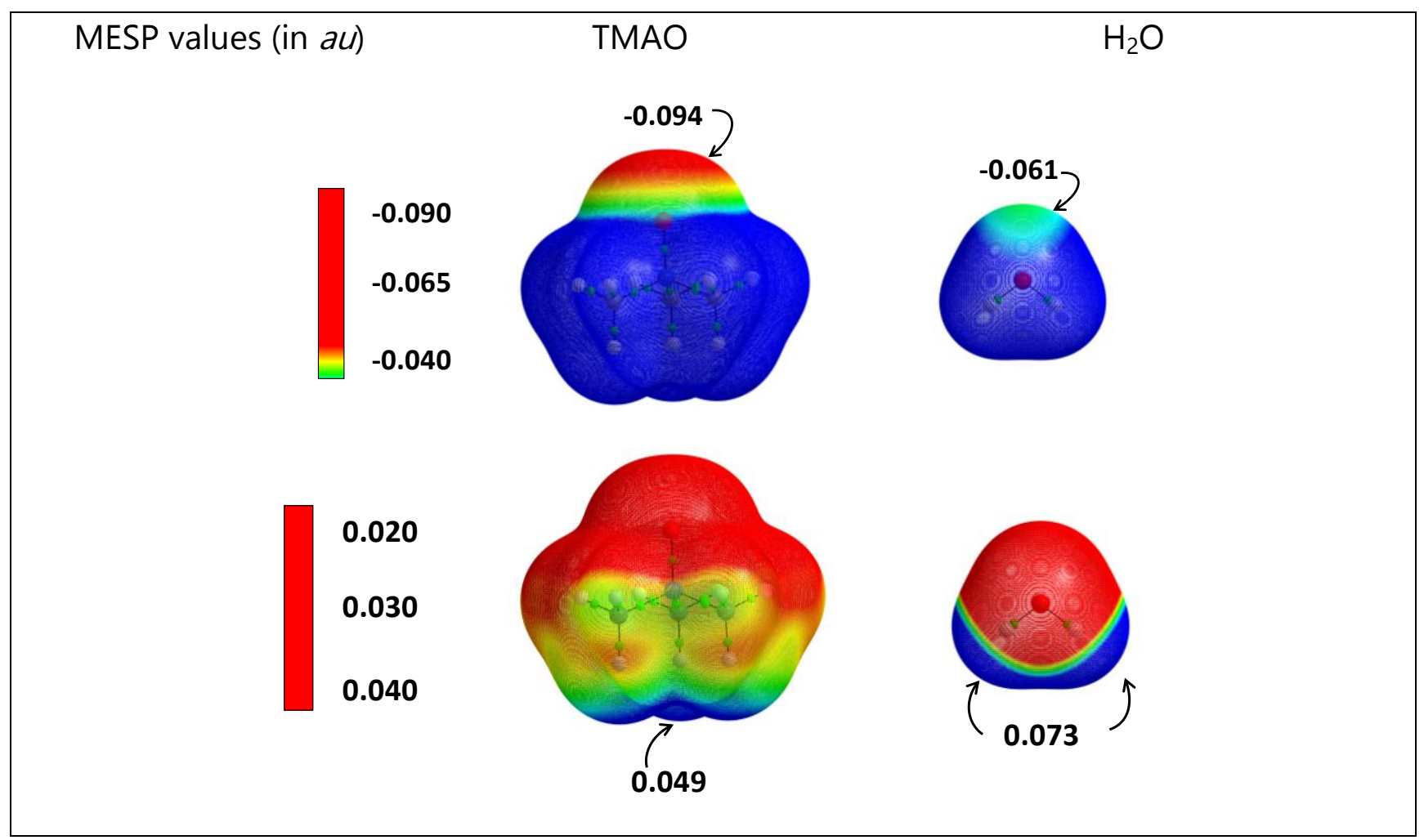

Figure 5: MESP features of the TMAO and water molecules.

In the case of TMAO: $\left(\mathrm{H}_{2} \mathrm{O}\right)_{4}$ complex, five isomers very close in energy, with $\Delta \mathrm{E} \leq 5.1 \mathrm{~kJ}^{\mathrm{mol}} \mathrm{mo}^{-}$ 1 were identified (See Supporting information S3). The most stable isomer found at the chosen level of theory consists of two water dimer, both simultaneously acting as hydrogen-bong donor with the oxygen atom of the TMAO solute, and as double hydrogenbond acceptor with two hydrogen atoms of methyl groups (See Supporting information S3 for the QTAIM features of the intermolecular interactions). Isomers involving higher fraction of hydrophilic water-solute interactions or higher fraction of hydrophobic water-solute interactions lies $13.5 \mathrm{~kJ}_{\mathrm{mol}}{ }^{-1}$ and $21.6 \mathrm{~kJ} . \mathrm{mol}^{-1}$ above the global minimum, respectively.

In the case of TMAO: $\left(\mathrm{H}_{2} \mathrm{O}\right)_{\mathrm{n}=5}$ to 9 complexes, at least $\mathrm{n}$ water-water interactions are identified in the most stable isomers on the basis of the QTAIM analysis. For $n=7-9$, among the most stable structures identified in the present study the ones involving the highest fraction of hydrophilic water-solute interactions also involve the highest fraction of hydrophobic water-solute interactions. 
Table 6: Structures of some of the most interesting TMAO: $\left(\mathrm{H}_{2} \mathrm{O}\right)_{4-9}$ complexes. See Supporting Information for energetic and topological features, as well as for the structures of other isomers. Additional features are presented in Supporting Information.

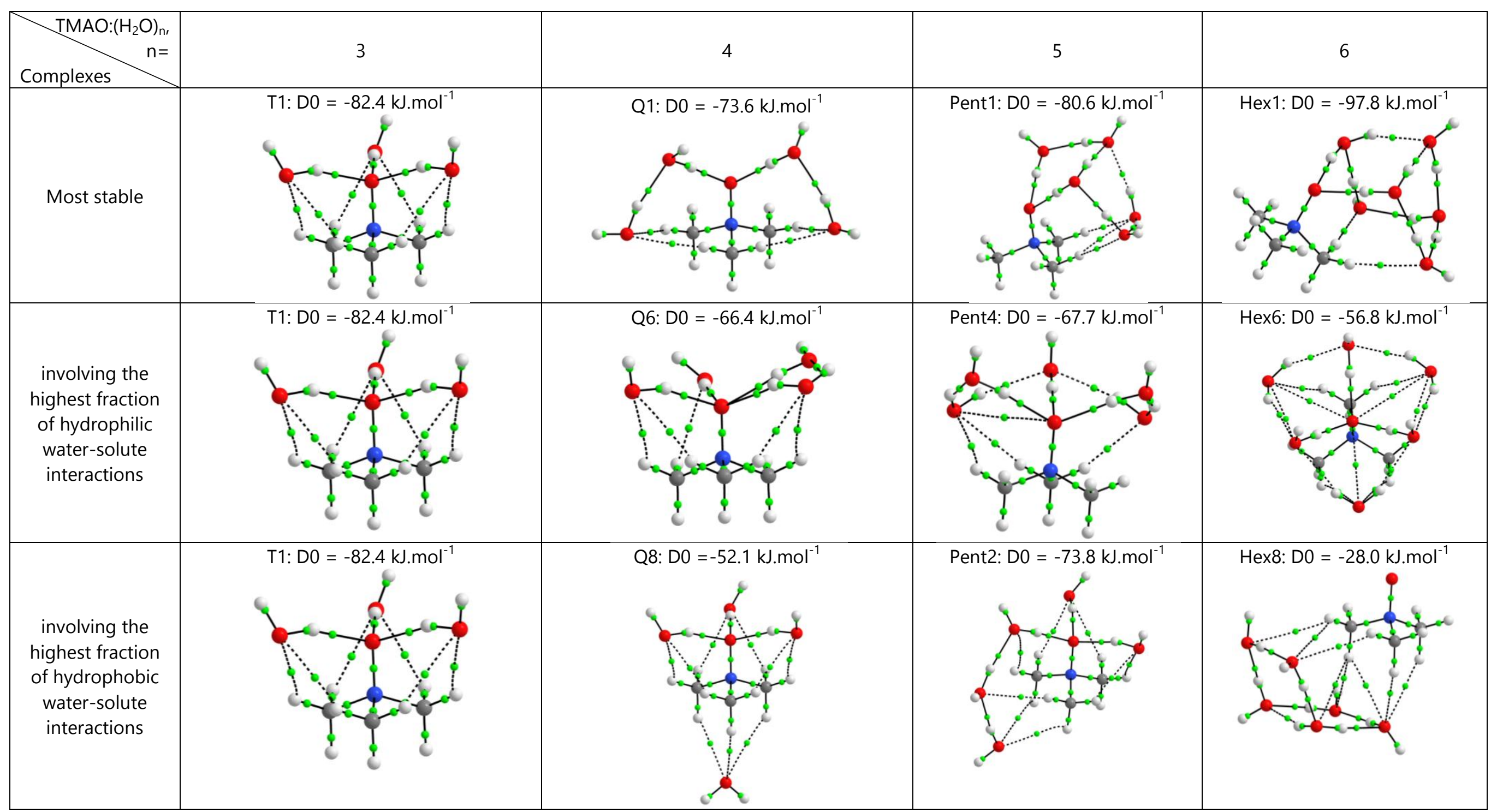




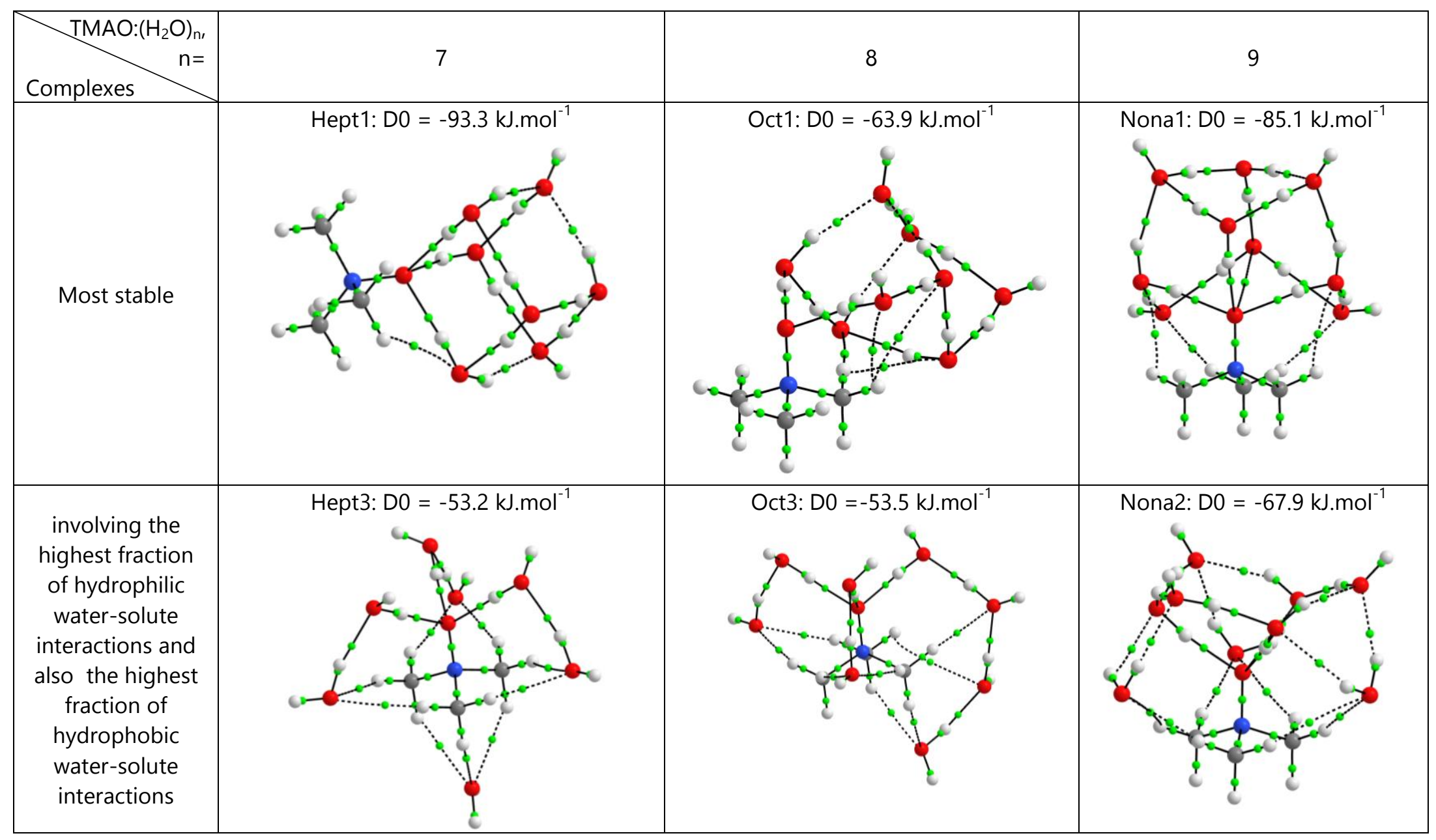




\section{Encapsulation}

From five water molecules, some isomers can be seen as the onset of encapsulation. It is therefore very interesting to look for the structure of a water cage allowing the encapsulation of the TMAO solute. For this study, two water cages were considered: $5^{12}$ and $5^{12} 6^{2}$ water cages constituting elementary assemblies of some water clathrates. ${ }^{27}$ The energy of the encapsulation ( $E_{\text {encapsulation}}$ ) was calculated as the difference between the sum of the energies of the isolated water cage and the TMAO on the one hand, and the energy of the TMAO@ $\left(\mathrm{H}_{2} \mathrm{O}\right)_{20,24}$, on the other hand. The D0 was calculated from the most stable $\left(\mathrm{H}_{2} \mathrm{O}\right)_{20,24}$ isomers. ${ }^{38}$ The most stable structures and energetics are presented in Table 7 , and the topological analysis as well as additional isomers are presented in Supporting Information.

Table 7: Stucture and energetics TMAO@ $\left(\mathrm{H}_{2} \mathrm{O}\right)_{20,24}$ of the complexes. Additional features are presented in Supporting Information.

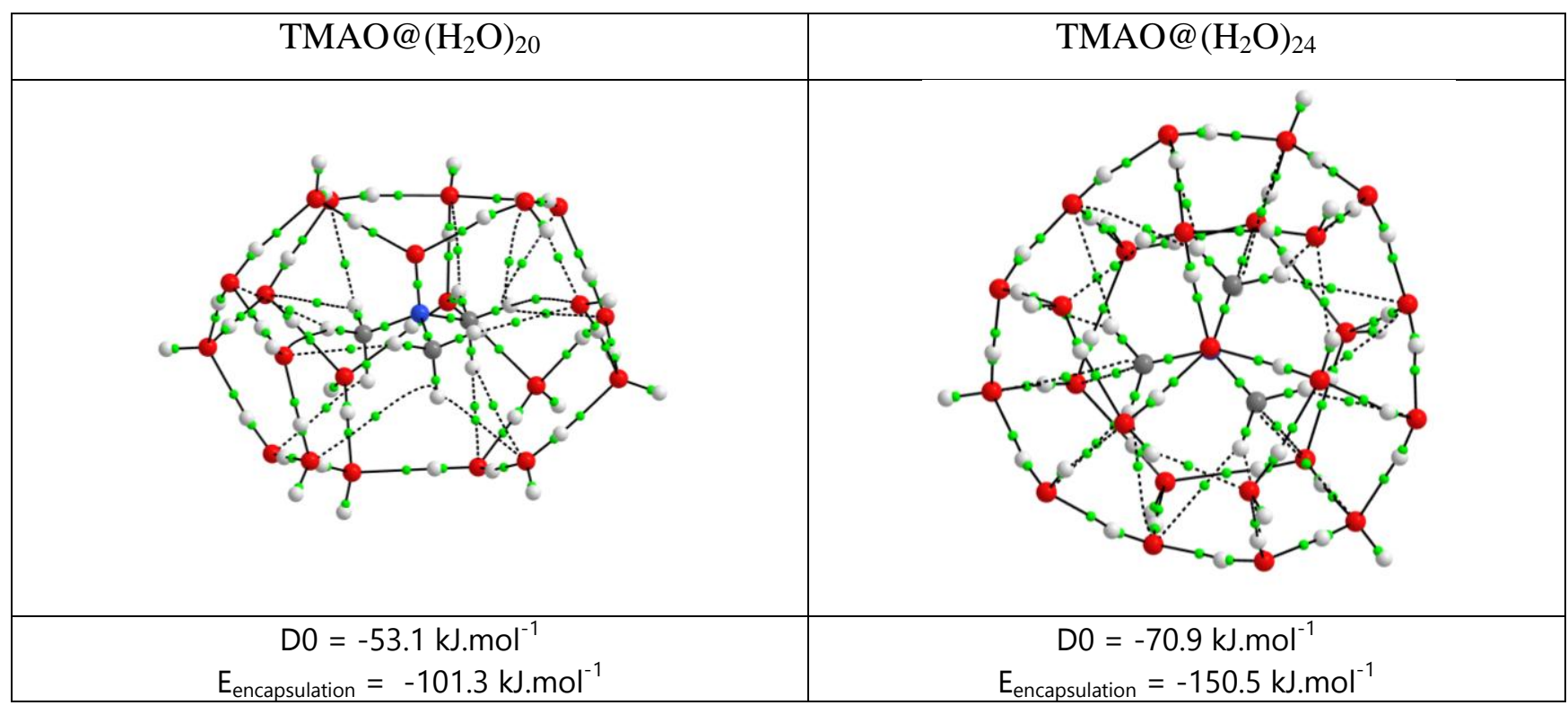

The presence of TMAO inside the $\left(\mathrm{H}_{2} \mathrm{O}\right)_{20}$ water cage causes a breakdown of the hydrogen bonding network between the water molecules. However, very strong interactions, characterized by high values of electronic densities at BCP (0.069 and 0.040) are established between the oxygen atom of the TMAO and two adjacent water molecules. Nineteen watersolute interactions are identified within the QTAIM framework, as well as twenty-seven water-water interactions (as a comparison, thirty-five hydrogen bondings were identified in the most stable $\left(\mathrm{H}_{2} \mathrm{O}\right)_{20}$ isomer $\left.{ }^{39}\right)$. Finally, the complex is characterized by a very high encapsulation energy $\left(E_{\text {encapsulation }}=-101.3 \mathrm{~kJ} \cdot \mathrm{mol}^{-1}\right)$. The value of D0 calculated from the most stable $\left(\mathrm{H}_{2} \mathrm{O}\right)_{20}$ isomer (edge-sharing) is also strongly negative (D0 $\left.=-53.1 \mathrm{~kJ} \cdot \mathrm{mol}^{-1}\right)$. This shows that the breakdown of the network of hydrogen bonds between water molecules for encapsulation of amphiphilic solute is energetically favorable. Another isomer without breakage of the hydrogen bonding network was obtained, but the size of the cavity was notably bigger than the of the empty cage. This results in a slight destabilization of the structure (D0 $=-38.3 \mathrm{~kJ}_{\mathrm{mol}}{ }^{-1}$, Structure 1_20_2 in Supporting Information) 
The insertion of the TMAO into the $\left(\mathrm{H}_{2} \mathrm{O}\right)_{24}$ cage does not lead to any breakage of the hydrogen bond between the water molecules. The QTAIM analysis identifies three very strong interactions between water molecules and the oxygen atom of the TMAO $(\rho(r)=$ 0.052). Eighteen other water-solute interactions involving the hydrogen atoms of the TMAO are also identified, as well as thirty-six interactions between water molecules (See Supporting Information). The encapsulation energy is even higher than in the case of the TMAO@ $\left(\mathrm{H}_{2} \mathrm{O}\right)_{20}$ complex, with $E_{\text {encapsulation }}=-150.5 \mathrm{~kJ}_{\mathrm{mol}}{ }^{-1}$. Furthermore, comparing to the most stable $\left(\mathrm{H}_{2} \mathrm{O}\right)_{24}$ isomer, the binding energy for the TMAO@ $\left(\mathrm{H}_{2} \mathrm{O}\right)_{24}$ complex is particularly favorable to the encapsulation, with $\mathrm{D} 0=-70.9 \mathrm{~kJ} \cdot \mathrm{mol}^{-1}$.

\section{Discussion}

Fifty one TMAO: $\left(\mathrm{H}_{2} \mathrm{O}\right)_{n}$ complexes were finally investigated. To better understand the origin of the stability of the various isomers identified, we sought to determine the relative influence of intermolecular water-water, water-solute interactions with the hydrophilic part of the TMAO, and water-solute interactions with the hydrophobic part of the TMAO. To this end, all intermolecular BCPs were considered, and it was assumed that the sum of electron density at these intermolecular BCPs was a good indicator of the strength of interactions. To validate this assumption, the sum of $\Sigma \rho$ at intermolecular BCPs was plotted as a function of the interaction energy (Figure 6A and Supporting Information S10). The linear relationship observed confirms that intermolecular BCPs may be used as quantitative indicators of the strength of the interactions.

In the most stable isomers (Figure 6B), hydrophilic interactions dominate: for complexes containing up to 4 water molecules, water-soluble interactions with the hydrophilic part of the TMAO are dominant. For complexes containing more than five water molecules, waterwater interactions become dominant in the most stable isomers. They are maximum for the TMAO: $\left(\mathrm{H}_{2} \mathrm{O}\right)_{20}$ complexes, where they represent more than $80 \%$ of intermolecular interactions. It should be noted that in all these most stable isomers, there is a significant fraction of water-solute interaction with the hydrophobic part of the TMAO. For small complexes, we obtained isomers for which the water-solute interaction fraction with the hydrophobic part of the TMAO was significant. These isomers are never the most stable, but they could play a role in certain chemical processes, or be observed experimentally under certain conditions. Figure $6 \mathrm{C}$ shows how the intermolecular interactions are distributed in these complexes. As the size of the complexes increases, the fraction of these interactions decreases, particularly in favor of water-water interactions. This may be explained by the fact that most of these isomers involve a water cluster interacts with the solute that have been obtained, with little disruption of the hydrogen bonding network between the water molecules. Figure 6D shows the distribution of interactions in isomers for which hydrophilic water-solute interactions are the highest. For complexes containing up to three water 
molecules, these are the most stable isomers, and the fraction of these interactions is more than $60 \%$. From the pentahydrated complex, the fraction of these hydrophilic water-solute interactions decreases, with a concomitant increase of water-water interactions.

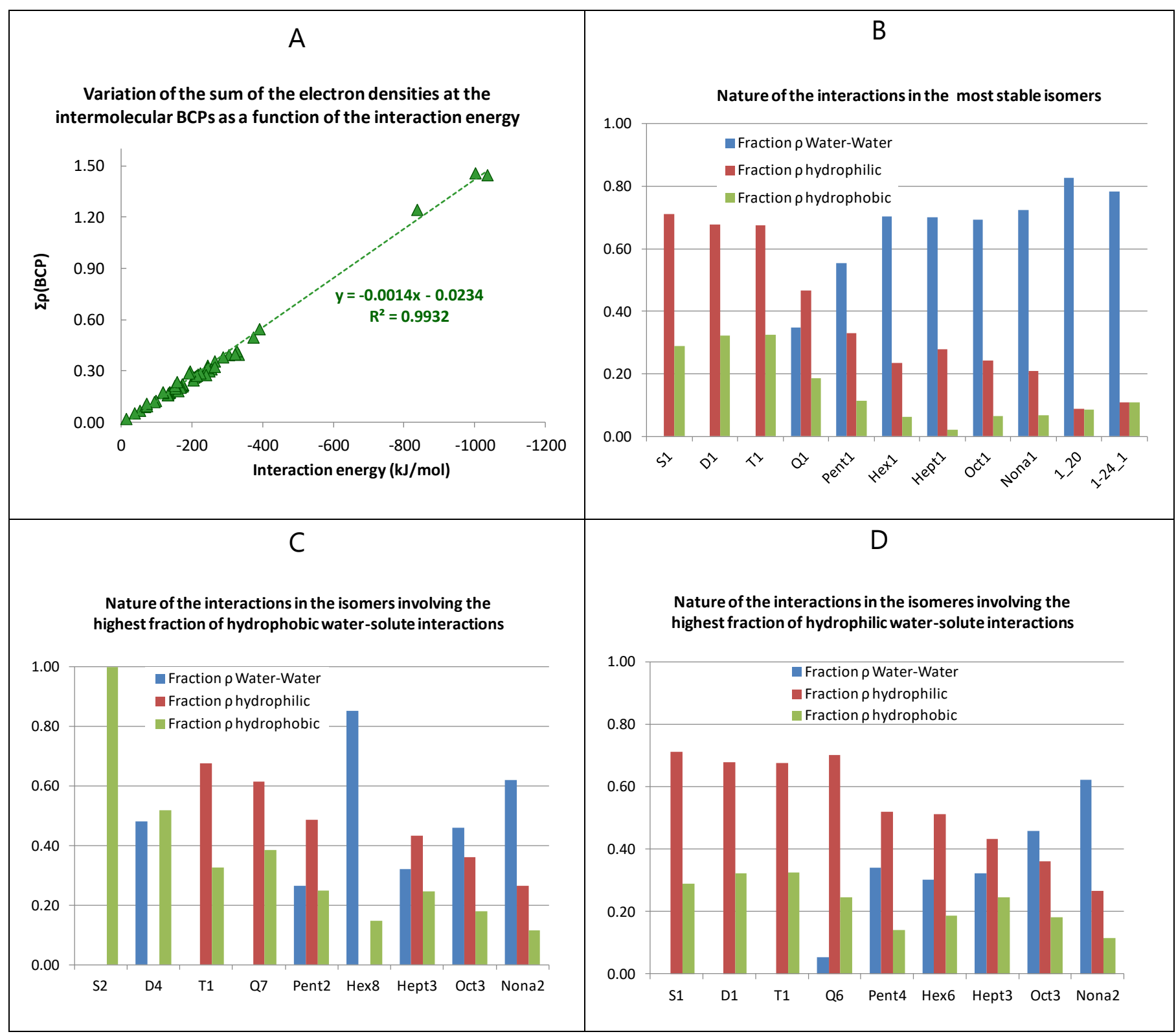

Figure 6: Characterization of the intermolecular interactions in the TMAO: $\left(\mathrm{H}_{2} \mathrm{O}\right)_{n}$ complexes, $1 \leq n \leq 24$. More data are given in Supporting Information S10.

Thus, all three types of intermolecular interactions are important in these complexes. Not surprisingly, the isomers that maximize hydrophilic water-water or water-solute interactions are the most stable. However, in all the most stable isomers obtained, there is also a fraction (at least $10 \%$ ) of hydrophobic interactions, even in the largest complexes.

Finally, we also sought to determine whether it was possible to predict the minimum cage for encapsulation of TMAO from the study of the smallest isomers, and more precisely the isomers of the monohydrate complex. Hydration of hydrophobic solutions is generally considered to be governed by the existence of an exclusion volume around the solute, into 
which water molecules cannot penetrate. The study of the distance between the water molecules and the solute in the S1, S2 isomers as well as in the two transition states TS1 and TS2 could therefore provide information on the minimum size of a water cage allowing complete encapsulation of the solute.

Figure 7A shows all the monohydrate isomers (minimum and TS) superimposed, taking into account the symmetry of the solute. The distances between oxygen atoms of the water molecules and the nitrogen atom have been reported: they are $3.16 \AA$ for $\mathrm{S} 1,3.76 \AA$ for S2, $3.94 \AA$ for TS2 and $4.61 \AA$ for TS1. The diameter of the $\left(\mathrm{H}_{2} \mathrm{O}\right)_{20}$ water cage (Figure 7B) is 7.6 $\AA$. The cavity of the $\left(\mathrm{H}_{2} \mathrm{O}\right)_{24}$ water cage (Figure $7 \mathrm{C}$ ) has a rectangular parallelepiped shape of $7.6 \times 6.0 \times 9.1$ size. An "exclusion volume" for water molecules around the TMAO can be defined, and superimposed on the two water cages (Figure 7D and 7E). The volume fits in the $\left(\mathrm{H}_{2} \mathrm{O}\right)_{24}$ cage but not in the $\left(\mathrm{H}_{2} \mathrm{O}\right)_{20}$ cage. It may thus be hypothesized, from the study of the geometric features of the TMAO: $\left(\mathrm{H}_{2} \mathrm{O}\right)$ isomers, that the $\left(\mathrm{H}_{2} \mathrm{O}\right)_{20}$ cage is too small to encapsulate the TMAO, unlike the $\left(\mathrm{H}_{2} \mathrm{O}\right)_{24}$ cage. This indeed corresponds to what is obtained after geometry optimizations of the TMAO@ $\left(\mathrm{H}_{2} \mathrm{O}\right)_{20,24}$ species: the encapsulation of the TMAO in the $\left(\mathrm{H}_{2} \mathrm{O}\right)_{20}$ cage leads to the rupture of the hydrogen bonding network between water molecules and the opening of the cage. On the other hand, the hydrogen bonding network between water molecules is maintained in the TMAO@ $\left(\mathrm{H}_{2} \mathrm{O}\right)_{24}$ complex.

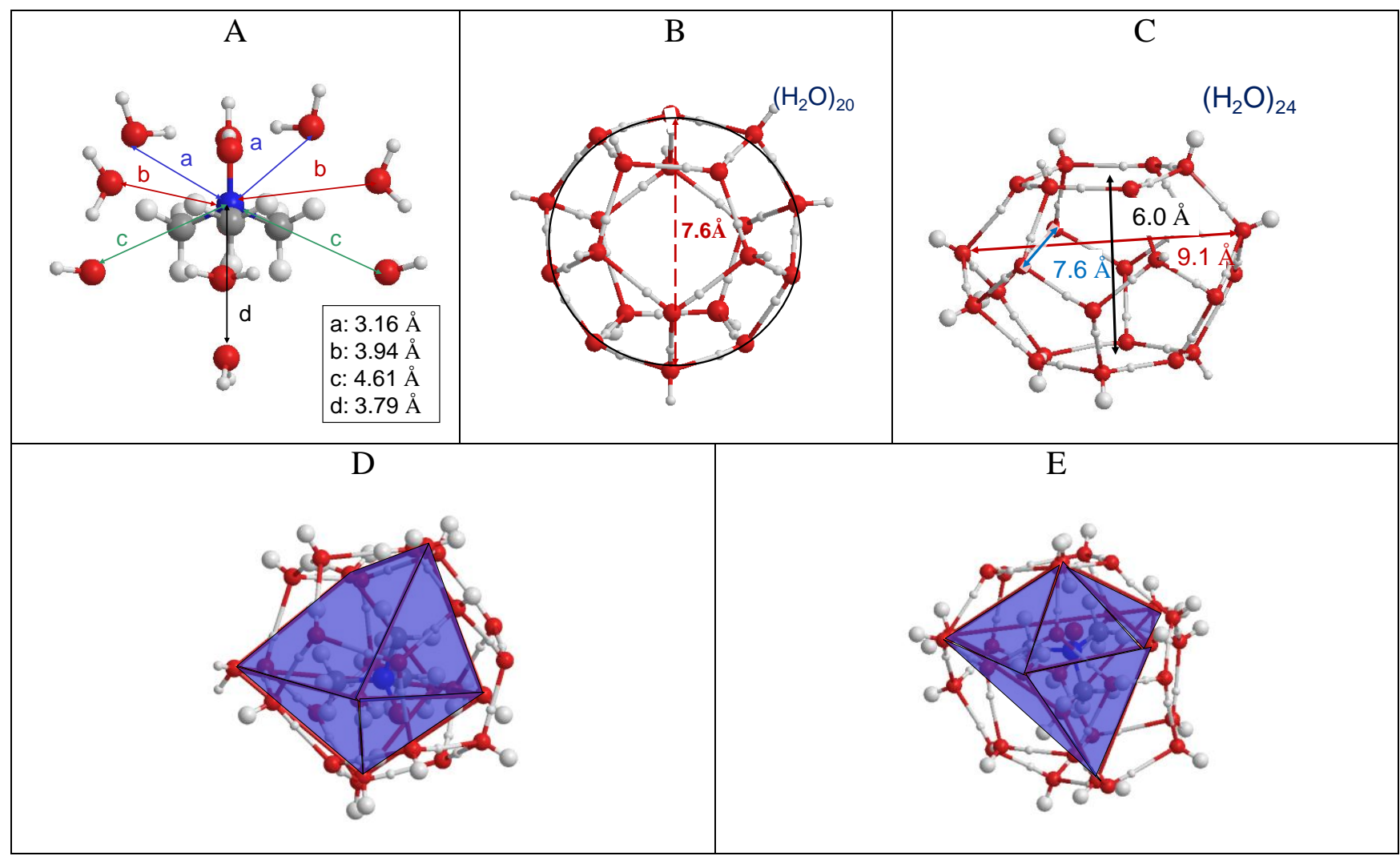

Figure 7: Comparison of water-solute distances in isomers S1, S2, TS1 and TS2 with the sizes of the water cages $\left(\mathrm{H}_{2} \mathrm{O}\right)_{20}$ and $\left(\mathrm{H}_{2} \mathrm{O}\right)_{24}$ to understand the minimal size of the water cage enabling the encapsulation of the solute (See text for more details). 


\section{Conclusion}

The MESP analysis of isolated solutes makes it possible to predict and explain the structures of the most favorable TMAO: $\left(\mathrm{H}_{2} \mathrm{O}\right)_{n}$ isomers. The oxygen atom of the TMAO is a particularly nucleophilic site, particularly suitable for acting as an hydrogen bond acceptor. In addition, the QTAIM analysis of hydrated complexes reveals that water molecules acting as hydrogen bond donors to the oxygen atom of the TMAO may be involved in other hydrogen bond interactions as hydrogen bond acceptors. A homodromic network of hydrogen bonds is thus formed, ${ }^{40}$ which is known to generally stabilize the complexes. ${ }^{41}$ The most stable isomer for the TMAO: $\left(\mathrm{H}_{2} \mathrm{O}\right)_{3}$ isomer was already identified in the literature: it is composed of three water molecules solely interacting with the TMAO. Such a structure significantly differ to "water segregation" 30-37 reported in the literature for the micro-hydration of several organic solutes. The presence of a stronger nucleophilic site on the TMAO than the oxygen atom of the water molecule may explain that the most stable isomer of the TMAO: $\left(\mathrm{H}_{2} \mathrm{O}\right)_{3}$ complex does not involve "water segregation". As the number of water molecule in the complex increases, water-water interactions are also formed in the most stable isomers identified in the present study. The QTAIM analysis of the intermolecular interactions suggests that, from $n=6$, water-water interactions overtake water-solute interactions in strength. However, unlike what is observed with some other solutes, the most stable isomers of TMAO: $\left(\mathrm{H}_{2} \mathrm{O}\right)_{6-9}$ complexes does not consist of the most stable $\left(\mathrm{H}_{2} \mathrm{O}\right)_{6-9}$ isomers slightly deformed and interacting with the solute. Instead, the arrangement of water molecules in the most stable TMAO: $\left(\mathrm{H}_{2} \mathrm{O}\right)_{n}$ isomers is notably different than the ones in the isolated $\left(\mathrm{H}_{2} \mathrm{O}\right)_{n}$ clusters.

The most stable isomer for the TMAO: $\left(\mathrm{H}_{2} \mathrm{O}\right)_{5}$ complex can be considered as the beginning of encapsulation (Figure 8): if we assimilate, as a first approximation, the TMAO molecule to a sphere centered on the nitrogen atom, about a fourth of this sphere is covered by an incomplete water layer. It is interesting to further notice that the beginnings of this encapsulation follow a spheroid arrangement of water molecules, with a diameter close to 9 $\AA$ in the equatorial axis (Figure 8).

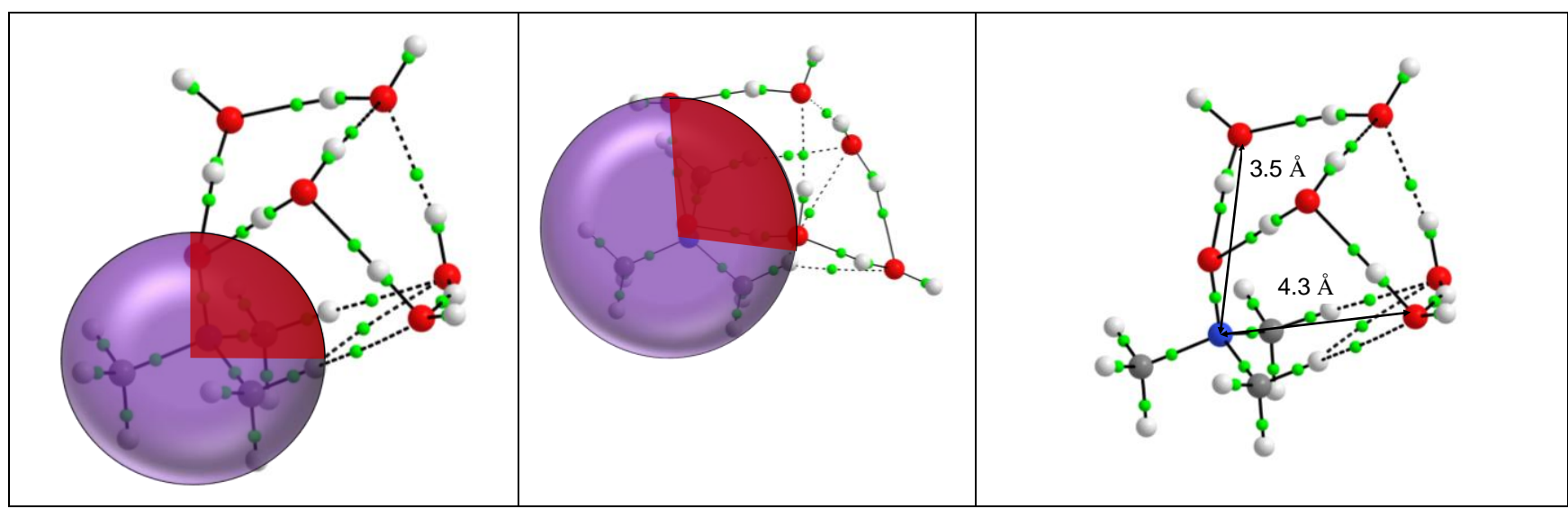

Figure 8: The most stable isomer of the TMAO: $\left(\mathrm{H}_{2} \mathrm{O}\right)_{5}$ complex can be seen as the beginning of the encapsulation of the solute. 
These characteristics are in line with those of the water cage which allows the encapsulation of the TMAO without breaking water-water interactions: the solute can be encapsulate within a $\left(\mathrm{H}_{2} \mathrm{O}\right)_{24}$ cage. This $5^{12} 6^{2}$ water cage has a spheroid shape with a diameter of $9.1 \AA$ in the equatorial axis and $6.0 \AA$ in the axial axis. Conversely, when the TMAO molecule is inserted inside the smaller $5^{12}$ water cage, some hydrogen bondings between water molecules are broken.

Thus, some small TMAO: $\left(\mathrm{H}_{2} \mathrm{O}\right)_{n}$ complexes share some geometric features with the smaller water cage allowing a total encapsulation of the solute. This geometric similarity pave the ways for a question: would it be possible to predict the structure of a water cage that can encapsulate the solute from complexes as small as TMAO: $\left(\mathrm{H}_{2} \mathrm{O}\right)$ ? The preliminary study presented here suggests that an extrapolation from the structure of the different forms (minima and TS) involving a single water molecule around the solute could provide initial clues as to the minimum approach distance of a water molecule, and therefore the minimum size of a water box that would be able to host the solute.

${ }^{1}$ Franks, F. (1965). Hydrophobic hydration and the effect of hydrogen bonding solutes on the structure of water. Annals of the New York Academy of Sciences, 125(2), 277-289.

2 Stillinger, F. H. (1973). Structure in aqueous solutions of nonpolar solutes from the standpoint of scaled-particle theory. In The Physical Chemistry of Aqueous System (pp. 43-60). Springer, Boston, MA.

${ }^{3}$ Djikaev, Y. S., \& Ruckenstein, E. (2016). Recent developments in the theoretical, simulational, and experimental studies of the role of water hydrogen bonding in hydrophobic phenomena. Advances in colloid and interface science, 235, 23-45.

${ }^{4}$ Hajari, T., \& Bandyopadhyay, S. (2017). Water structure around hydrophobic amino acid side chain analogs using different water models. J. Chem.Phys., 146(22), 225104.

${ }^{5}$ Chandler, D. (2005). Interfaces and the driving force of hydrophobic assembly. Nature, 4377059), 640.

${ }^{6}$ Remsing, R. C., \& Weeks, J. D. (2013). Dissecting hydrophobic hydration and association. J. Phys. Chem. $B, 117(49), 15479-15491$.

7 Ohto, T., Hunger, J., Backus, E. H., Mizukami, W., Bonn, M., \& Nagata, Y. (2017). Trimethylamine-Noxide: its hydration structure, surface activity, and biological function, viewed by vibrational spectroscopy and molecular dynamics simulations. Phys. Chem. Chem. Phys., 19(10), 6909-6920.

8 Imoto, S., Forbert, H., \& Marx, D. (2018). Aqueous TMAO solutions as seen by theoretical THz spectroscopy: hydrophilic versus hydrophobic water. Phys. Chem. Chem. Phys., 20(9), 6146-6158.

${ }^{9}$ Stirnemann, G., Duboué-Dijon, E., \& Laage, D. (2017). Ab Initio Simulations of Water Dynamics in Aqueous TMAO Solutions: Temperature and Concentration Effects. J. Phys. Chem.B, 121(49), 1118911197.

${ }^{10}$ Esser, A., Belsare, S., Marx, D., \& Head-Gordon, T. (2017). Mode specific THz spectra of solvated amino acids using the AMOEBA polarizable force field. Phys. Chem. Chem. Phys., 19(7), 5579-5590.

11 Munroe, K. L., Magers, D. H., \& Hammer, N. I. (2011). Raman spectroscopic signatures of noncovalent interactions between trimethylamine N-oxide (TMAO) and water. J. Phys. Chem.B, 115(23), 7699-7707. 
${ }^{12}$ Murray, J. S., \& Politzer, P. (2011). The electrostatic potential: an overview. Wiley Interdisciplinary Reviews: Computational Molecular Science, 1(2), 153-163.

13 Politzer, P., Murray, J. S., \& Clark, T. (2015). Mathematical modeling and physical reality in noncovalent interactions. J. mol. model., 21(3), 52.

${ }^{14}$ Politzer, P., \& Murray, J. S. (2018). The Hellmann-Feynman theorem: a perspective. J. mol. model., 24(9), 266.

15 Silvi, B., \& Savin, A. (1994). Classification of chemical bonds based on topological analysis of electron localization functions. Nature, 371(6499), 683.

${ }^{16}$ Savin, A., Nesper, R., Wengert, S., \& Fässler, T. F. (1997). ELF: The electron localization function. Angew. Chem. International Ed., 36(17), 1808-1832.

${ }^{17}$ Silvi, B. (2015). The Relevance of the ELF Topological Approach to the Lewis, Kossel, and Langmuir Bond Model. In The Chemical Bond I/ (pp. 213-247). Springer, Cham.

${ }^{18}$ Gillespie, R. J., \& Robinson, E. A. (2007). Gilbert N. Lewis and the chemical bond: The electron pair and the octet rule from 1916 to the present day. Journal of computational chemistry, 28(1), 87-97.

${ }^{19}$ Bader, R. F., Streitwieser, A., Neuhaus, A., Laidig, K. E., \& Speers, P. (1996). Electron delocalization and the Fermi hole. J. Am. Chem. Soc., 118(21), 4959-4965.

${ }^{20}$ M. J. Frisch, G. W. Trucks, H. B. Schlegel, G. E. Scuseria, M. A. Robb, J. R. Cheeseman, G. Scalmani, V. Barone, B. Mennucci, G. A. Petersson, H. Nakatsuji, M. Caricato, X. Li, H. P. Hratchian, A. F. Izmaylov, J. Bloino, G. Zheng, J. L. Sonnenberg, M. Hada, M. Ehara, K. Toyota, R. Fukuda, J. Hasegawa, M. Ishida, T. Nakajima, Y. Honda, O. Kitao, H. Nakai, T. Vreven, J. A. Montgomery, Jr., J. E. Peralta, F. Ogliaro, M. Bearpark, J. J. Heyd, E. Brothers, K. N. Kudin, V. N. Staroverov, R. Kobayashi, J. Normand, K. Raghavachari, A. Rendell, J. C. Burant, S. S. Iyengar, J. Tomasi, M. Cossi, N. Rega, J. M. Millam, M. Klene, J. E. Knox, J. B. Cross, V. Bakken, C. Adamo, J. Jaramillo, R. Gomperts, R. E. Stratmann, O. Yazyev, A. J. Austin, R. Cammi, C. Pomelli, J. W. Ochterski, R. L. Martin, K. Morokuma, V. G. Zakrzewski, G. A. Voth, P. Salvador, J. J. Dannenberg, S. Dapprich, A. D. Daniels, Ö. Farkas, J. B. Foresman, J. V. Ortiz, J. Cioslowski, and D. J. Fox, Gaussian 09 (Gaussian, Inc., Wallingford CT, 2009).

${ }^{21}$ Vydrov, O. A., \& Scuseria, G. E. (2006). Assessment of a long-range corrected hybrid functional. J. Chem.Phys., 125(23), 234109.

${ }^{22}$ Vydrov, O. A., Heyd, J., Krukau, A. V., \& Scuseria, G. E. (2006). Importance of short-range versus long-range Hartree-Fock exchange for the performance of hybrid density functionals. J. Chem.Phys. 125(7), 074106.

${ }^{23}$ Vydrov, O. A., Scuseria, G. E., \& Perdew, J. P. (2007). Tests of functionals for systems with fractional electron number. J. Chem.Phys., 126(15), 154109.

${ }^{24}$ Grimme, S., Ehrlich, S., \& Goerigk, L. (2011). Effect of the damping function in dispersion corrected density functional theory. Journal of computational chemistry, 32(7), 1456-1465.

${ }^{25}$ Noury, S., Krokidis, X., Fuster, F., \& Silvi, B. (1999). Computational tools for the electron localization function topological analysis. Computers \& chemistry, 23(6), 597-604.

${ }^{26}$ AlMAll (Version 17.11.14), Todd A. Keith, TK Gristmill Software, Overland Park KS, USA, 2017 (aim.tkgristmill.com)

${ }^{27}$ Sun, N., Li, Z., Qiu, N., Yu, X., Zhang, X., Li, Y., Yang, L., Luo, K., Huang, Q. \& Du, S. (2017). Ab Initio Studies on the Clathrate Hydrates of Some Nitrogen-and Sulfur-Containing Gases. J. Phys. Chem.A, 121(13), 2620-2626. 
${ }^{28}$ Wang, K., Li, W., \& Li, S. (2014). Generalized energy-based fragmentation CCSD (T)-F12a method and application to the relative energies of water clusters $(\mathrm{H} 2 \mathrm{O})$ 20. Journal of chemical theory and computation, 104), 1546-1553.

${ }^{29}$ Arunan, E., et al. (2011). Definition of the hydrogen bond (IUPAC Recommendations 2011). Pure and applied chemistry, 83(8), 1637-1641.

${ }^{30}$ Pérez, C., Neill, J. L., Muckle, M. T., Zaleski, D. P., Peña, I., Lopez, J. C., Alonso, J. L., \& Pate, B. H. (2015). Water-Water and Water-Solute interactions in Microsolvated Organic Complexes. Angew. Chem. International Ed. 127(3), 993-996.

31 Thomas, J., Sukhorukov, O., Jäger, W., \& Xu, Y. (2014). Direct spectroscopic detection of the orientation of free $\mathrm{OH}$ Groups in Methyl Lactate-(Water) 1, 2 Clusters: Hydration of a Chiral Hydroxy Ester. Angew. Chem. International Ed., 53(4), 1156-1159.

${ }^{32}$ Kalai, C., Zins, E. L., \& Alikhani, M. E. (2017). A theoretical investigation of water-solute interactions: from facial parallel to guest-host structures. Theor. Chem. Acc., 136(4), 48.

${ }^{33}$ Kalai, C., Alikhani, M. E., \& Zins, E. L. (2018). The molecular electrostatic potential analysis of solutes and water clusters: a straightforward tool to predict the geometry of the most stable micro-hydrated complexes of $\beta$-propiolactone and formamide. Theor. Chem. Acc., 137(11), 144.

34 Calvo, F., Bacchus-Montabonel, M. C., \& Clavaguéra, C. (2016). Stepwise hydration of 2aminooxazole: theoretical insight into the structure, finite temperature behavior and proton-induced charge transfer. J. Phys. Chem.A, 120(15), 2380-2389.

35 Miliordos, E., Aprà, E., \& Xantheas, S. S. (2016). A New, Dispersion-Driven Intermolecular Arrangement for the Benzene-Water Octamer Complex: Isomers and Analysis of their Vibrational Spectra. Journal of Chemical Theory and Computation, 12(8), 4004-4014.

${ }^{36}$ Calvo, F., \& Bacchus-Montabonel, M. C. (2018). Size-Induced Segregation in the Stepwise Microhydration of Hydantoin and Its Role in Proton-Induced Charge Transfer. J. Phys. Chem.A, 122(6), 1634-1642.

${ }^{37}$ Riffet, V., Frison, G., \& Bouchoux, G. (2018). Quantum-Chemical Modeling of the First Steps of the Strecker Synthesis: From the Gas-Phase to Water Solvation. J. Phys. Chem.A, 122(6), 1643-1657.

${ }^{38}$ Wang, K., Li, W., \& Li, S. (2014). Generalized energy-based fragmentation CCSD (T)-F12a method and application to the relative energies of water clusters $\left(\mathrm{H}_{2} \mathrm{O}\right)_{20}$. Journal of chemical theory and computation, 104), 1546-1553.

${ }^{39}$ Fanourgakis, G. S., Apra, E., \& Xantheas, S. S. (2004). High-level ab initio calculations for the four low-lying families of minima of $\left(\mathrm{H}_{2} \mathrm{O}\right)_{20}$. I. Estimates of MP2/CBS binding energies and comparison with empirical potentials. The Journal of chemical physics, 121(6), 2655-2663.

${ }^{40}$ Xantheas, S. S. (2000). Cooperativity and hydrogen bonding network in water clusters. Chemical Physics, 258(2-3), 225-231.

${ }^{41}$ A discussion on this point, as well as "limit cases" are presented in the following article: GuevaraVela, J. M. et al. (2016). Hydrogen bond cooperativity and anticooperativity within the water hexamer. Phys. Chem. Chem. Phys., 18(29), 19557-19566. 